\title{
REVIEW
}

\section{Novel cancer therapies and their association with diabetes}

\author{
Afreen Idris Shariff', Sohail Syed ${ }^{2}$, Rebecca A Shelby³, Jeremy Force ${ }^{4}$, Jeffrey Melson Clarke ${ }^{4}$, David D'Alessio ${ }^{1}$ and \\ Leonor Corsino ${ }^{1}$
}

1Division of Endocrinology, Metabolism and Nutrition, Duke University School of Medicine, Durham, North Carolina, USA 2Virginia Commonwealth University, Richmond, Virginia, USA

${ }^{3}$ Department of Psychiatry and Behavioral Sciences, Duke University School of Medicine, Durham, North Carolina, USA

${ }^{4}$ Division of Medical Oncology, Duke University School of Medicine, Durham, North Carolina, USA

Correspondence should be addressed to A I Shariff: afreen.shariff@duke.edu

\begin{abstract}
Over the last decade, there has been a shift in the focus of cancer therapy from conventional cytotoxic drugs to therapies more specifically directed to cancer cells. These novel therapies include immunotherapy, targeted therapy and precision medicine, each developed in great part with a goal of limiting collateral destruction of normal tissues, while enhancing tumor destruction. Although this approach is sound in theory, even new, specific therapies have some undesirable, 'off target effects', in great part due to molecular pathways shared by neoplastic and normal cells. One such undesirable effect is hyperglycemia, which results from either the loss of immune tolerance and autoimmune destruction of pancreatic $\beta$-cells or dysregulation of the insulin signaling pathway resulting in insulin resistance. These distinct pathogenic mechanisms lead to clinical presentations similar to type 1 (T1DM) and type 2 (T2DM) diabetes mellitus. Both types of diabetes have been reported in patients across clinical trials, and data on the mechanism(s) for developing hyperglycemia, prevalence, prognosis and effect on cancer mortality is still emerging. With the rapidly expanding list of clinical indications for new cancer therapies, it is essential to understand the impact of their adverse effects. In this review, we focus on hyperglycemia and diabetes related to cancer therapies, describe what is known about mechanism(s) leading to dysregulated glucose metabolism and provide a guide to management of complex oncology patients with a new diagnosis of diabetes.
\end{abstract}

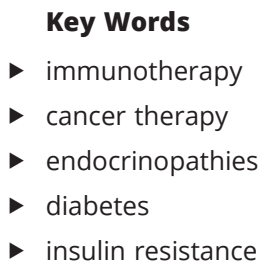

Journal of Molecular Endocrinology (2019) 62, R187-R199

\section{Introduction}

Over the last decade, the field of oncology has seen the emergence of new therapeutic modalities such as immunotherapy, targeted therapy and precision medicine (Simpson et al. 2016). These approaches have become a mainstay of cancer therapy because of better tolerability, improved efficacy and less toxicity compared to conventional cancer treatments (Simpson et al. 2016, Au et al. 2017). Broadly, the concept behind immunotherapy is to engage the immune system to destroy cancer cells. For example, the now widely used immune check point inhibitors (ICPI) loosen T-cell tolerance by blocking key regulatory proteins that are critical for 'self-identification'. By removing the breaks on the immune system, cancer cells that have breached immune surveillance are targeted 
and destroyed (Salvatore et al. 2013). However, this mechanism can also lead to unwanted immune actions and a number of autoimmune endocrinopathies have been described with immunologic modulation including T1DM (Hughes et al. 2015, Barroso-Sousa et al. 2018). Although T1DM is a rare complication of ICPI, there is an interest in understanding the autoimmune mechanism, as well as concern about the management and longterm prognosis for patients who develop this side effect (Jonathan et al. 2017). These concerns are amplified by the success of these agents in treating cancer and their expanding use. Following the introduction of the first agent, ipilimumab in 2011 for metastatic melanoma, multiple agents targeting other key immune targets like the programmed cell death/ligand (PD1/PDL1) axis have entered the market (Culver et al. 2011). In the last 7 years, nivolumab, pembrolizumab, durvalumab, atezolizumab and tremelimumab have become available and their clinical applications are expanding rapidly to include metastatic melanoma, non-small-cell lung cancer, renal cell carcinoma, bladder carcinoma, head and neck cancer and lymphomas (https://www.fda.gov/Drugs/ InformationOnDrugs/ApprovedDrugs/ucm279174.htm, accessed 3/17/18).

Unlike immunotherapy, targeted cancer therapy is directed at specific molecular pathways involved in carcinogenesis, including regulation of cell growth, apoptosis and cancer progression (Pérez-Herrero \& Fernández-Medarde 2015). While theoretically specific and effective, in practice there is some overlap of the targets of these signaling pathways in cancer cells and normal cells raising the potential for adverse effects including hyperglycemia. For example, the insulin signaling pathway is a key pathway utilized by cancer cells to promote cellular proliferation, growth and angiogenesis. Thus, some new drugs that target the insulin signaling pathway carry a risk for causing insulin resistance, impaired insulin secretion or both and have been associated with the development of both T1DM and T2DM (Yang \& Yee 2012).

It is important to note that a concurrent diagnosis of diabetes is associated with increased risk of all-cause mortality in patients with cancer. A large body of evidence suggests that women with diabetes who develop breast, colon, pancreatic, liver or endometrial cancer have a higher all-cause mortality (El-Seraq et al. 2006). Furthermore, in men the risk for all-cause mortality is increased in patients diagnosed with diabetes and colon, liver or pancreatic cancer (Campbell et al. 2012). These associations suggest an adverse impact of diabetes on cancer survival. However, the impact of new-onset diabetes from these novel cancer therapies on preexisting cancer is still unknown due to the lack of long-term safety and mortality data. In this review, we aim to provide readers with a summary of currently available information regarding cancer therapies and their association with diabetes. Special attention will be given to novel drugs and their effects.

\section{Cancer therapies that reduce insulin secretion}

\section{Immune check-point inhibitors (ICPI)}

Immune checkpoint inhibitors (ICPI) are immunotherapy agents that work primarily by using the immune system to target and eradicate cancer cells. Currently, ICPI include three drug classes of monoclonal antibodies named after their targets: anti-cytotoxic T-lymphocyte 4-antigen antibody (anti-CTLA-4 Ab), programmed cell death-1 inhibitors (PD-1 inhibitors) and programmed cell death ligand-1 inhibitors (PDL-1 inhibitors) (Diesendruck \& Benhar 2017). Examples of drugs in these categories are ipilimumab and tremelimumab (anti-CTLA-4 Ab), nivolumab and pembrolizumab (PD-1 inhibitors), atezolizumab and durvalumab (PDL-1 inhibitors) (Ryder et al. 2014, Robert et al. 2015; Table 1). The first drug approved by the USA Food and Drug Association (FDA) in this category was anti-CTLA-4 inhibitor ipilimumab, based on observations that it increased disease-free survival from a median of 6.4-10.1 months in metastatic melanoma patients (Hodi et al. 2010). Additional drugs in the category of ICPI have entered the market in less than a decade and were projected to expand from a total market share of 1 billion dollars in 2013 to 7 billion dollars by 2020 (Webster 2014).

ICPI have undesired off-target effects, collectively referred to as immune-related adverse events (irAE). Overall, irAE are seen in approximately $50-60 \%$ of patients treated with ICPI, with some of the most commonly reported morbidity caused by autoimmune colitis and hepatitis (29-32\% and 6-8\% of treated patients respectively), dermatitis (43-45\% of treated patients), and less commonly endocrinopathies (6-8\% of treated patients) (Byun et al. 2017). However, with their growing use in clinical practice, emerging data from observational studies and clinical trials suggest that endocrinopathies may be more common than previously reported (BarrosoSousa et al. 2018).

Endocrinopathies reported in clinical trials include lymphocytic hypophysitis (0-17\%), Grave's disease 
Table 1 Cancer therapies that reduce insulin secretion.

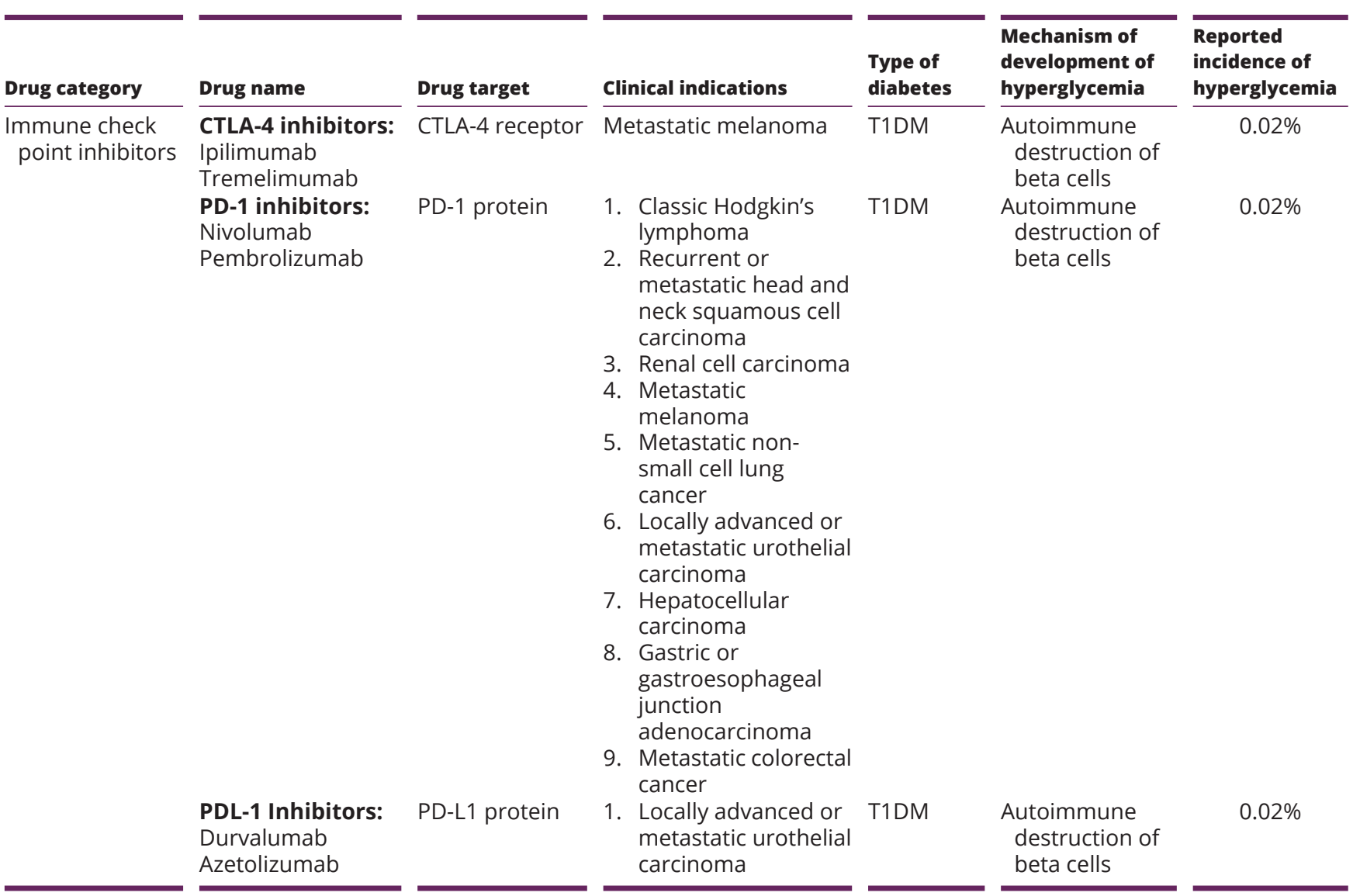

and thyroiditis (6\%-20\%), less commonly reported primary adrenal insufficiency and type 1 diabetes (T1DM) (Wolchok et al. 2010). More recently, in a systematic review of ten randomized control trials where the relative risk of endocrinopathies observed with single agent ICPI was compared to placebo or control it was noted that the relative risk of all-grade hypothyroidism, hyperthyroidism, hypophysitis and adrenal insufficiency was 8.26 (95\% CI: 4.67-14.62); 5.48 (95\% CI: 1.33-22.53); 22.03 (95\% CI: 8.52-56.94) and 3.87 (95\% CI: 1.12-13.41) respectively (AbdelRahman et al. 2016). Although T1DM was reported in several of the clinical trials included in this systematic review, the data are sparse and were insufficient to estimate a relative risk (Abdel-Rahman et al. 2016, Barroso-Sousa et al. 2018).

Despite uncertain data on the true prevalence of T1DM among ICPI users, PD-1 inhibitors have been associated with rapid-onset hyperglycemia within days to weeks after the first dose nivolumab or pembrolizumab (Hughes et al. 2015). These patients also present with features and biochemical findings seen in T1DM. For example, patients who develop hyperglycemia following ICPI use

(c) 2019 Society for Endocrinology Published by Bioscientifica Ltd. Printed in Great Britain present with acute-onset hyperglycemia associated with life-threatening complications like diabetic ketoacidosis (DKA) that can be indistinguishable from new-onset T1DM (Hughes et al. 2015). In a case series of five hyperglycemic PD-1 inhibitor-treated patients, three of five patients had positive glutamic acid decarboxylase-65 antibodies (GAD$65 \mathrm{Ab}$ ). Most patients presented with DKA, undetectable C-peptide levels and positive GAD-65 Ab similar to classic T1DM (Hughes et al. 2015). At this time, there are limited data on reversal of T1DM with withdrawal of ICPI and reported patients remain treated with insulin (Hughes et al. 2015).

\section{Mechanism for development of autoimmune diabetes}

ICPI block immune inhibitory mechanisms, constricting the immunologic definition of self, and potentially allowing predisposition of autoimmunity to become unmasked. Specifically, two key inhibitory nodes, CTLA-4 and PD-1, are blocked, permitting distinct patterns of T-cell activation. Blockade of the CTLA- 4 pathway causes general activation of the immune system and blockade of 
PD-1/PDL-1 pathway allows cancer cells to be identified as non-self-antigens (Boutros et al. 2016).

CTLA-4 is cell-surface receptor expressed on the surface of the T-cells involved in the early activation of the immune system. Antigen-presenting cells (APC) present antigens (Ag) via the major histocompatibility complex (MHC) to the inactivated T-lymphocyte. T-lymphocytes have two key regulatory receptors, inhibitory CTLA-4 and activating CD28. When the receptor B7 located on the APC binds to CTLA-4 receptor, the T-cell is inactivated and when $\mathrm{B} 7$ binds to CD28 the T-cell gets activated. In order to activate the T-cell, B7 must bind to CD28. Ipilimumab (monoclonal antibody to CTLA-4 receptor) enables this by binding to the CTLA-4 receptor allowing the B7 ligand to freely engage with CD28 receptor activating the T-cells (Boutros et al. 2016; Fig. 1).

In contrast, blocking the PD-1 pathway allows the immune system to recognize and destroy cancer cells as non-self-antigens. PD-ligand is expressed on cancer cells which bind to the PD-1 receptors expressed on the surface of activated T-cells. This results in the deactivation of the T-cell allowing cancer cell survival. For cancer cells to be detected and destroyed, T-cells must identify them as non-self-antigens, which is made possible by the binding of PD-1 and PDL-1 monoclonal antibodies to these

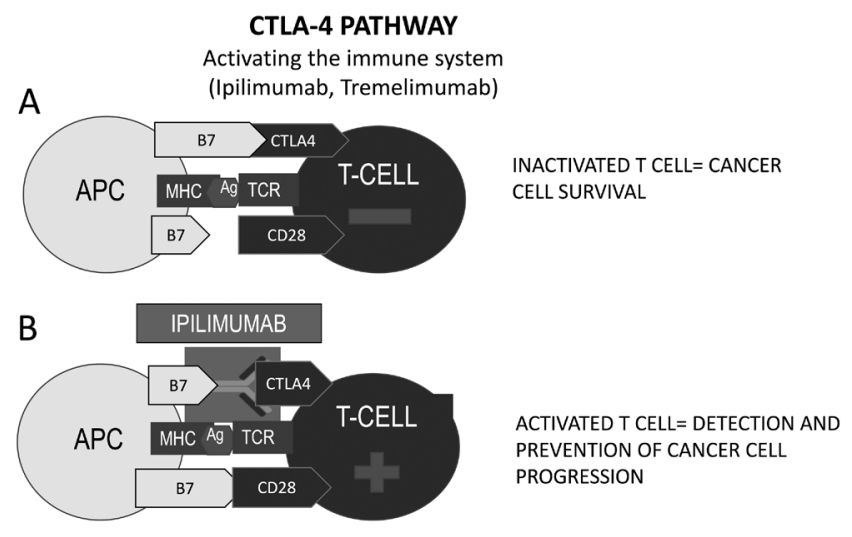

\section{Figure 1}

CTLA-4 is cell-surface receptor expressed on the surface of the T cells involved in the early activation of the immune system. Antigen-presenting cells (APC) present antigens (Ag) via the Major Histocompatibility Complex (MHC) to the inactivated T-lymphocyte. T-lymphocytes have two key regulatory receptors, inhibitory CTLA-4 and activating CD28. (A) Receptor B7 located on the APC binds to inactivating CTLA-4 receptor, and the T-cell is inactivated allowing cancer cell survival. (B) When ipilimumab (monoclonal antibody to CTLA-4 receptor) binds to the CTLA-4 receptor, T-cell activating B7 ligand freely engages with CD28 receptor activating the T-cells resulting in cancer cell destruction. Adapted/Translated by permission from Macmillan Publishers Ltd: Nature, Nature reviews clinical Oncology, Safety profiles of anti-CTLA-4 and anti-PD-1antibodies alone and in combination. Boutros C, Tarhini A, Routier E, Lambotte O, Ladurie FL, Carbonnel F, Izzeddine H, Marabelle A, Champiat S, Berdelou A et al. 2016. receptors. This allows for cancer cell detection (Boutros et al. 2016; Fig. 2).

Despite a general understanding of how ICPI modulates the immune system and targets cancer cells, the mechanism by which they cause autoimmune endocrinopathies, including what may be a version of T1DM, is not known. Some possibilities can be inferred from experimental data reported prior to the development of ICPI as anti-cancer drugs. In a study of autoimmune diabetes in non-obese diabetes (NOD) mice, it was noted that the majority of animals given PD-1 (76.5\%) and PD-L1 (82.4\%) inhibitors developed T1DM within a week compared to only $20 \%$ in non-treated littermates. Of note, CTLA-4 blockade in NOD mice did not affect the rate of diabetes onset compared to controls, supporting the clinical observation that T1DM is seen mostly in patients receiving PD-1 or PD-L1 inhibitors (Delovitch \& Singh 1997, Ansari et al. 2003). Whether T1DM from these agents in humans follows the same phenomena as reported in NOD mice is an area under investigation.

At this time, there is consensus that ICPI raise the risk for autoimmune T1DM. However, the clinical course, biochemical markers, outcomes and long-term follow-up of such patients are areas of uncertainty and limited knowledge. In the future, as more data emerge,
PD-1 PATHWAY

Recognizing cancer cells as non-self Antigens (Nivolumab, Pembrolizumab, Azetolizumab, Durvalumab)

A
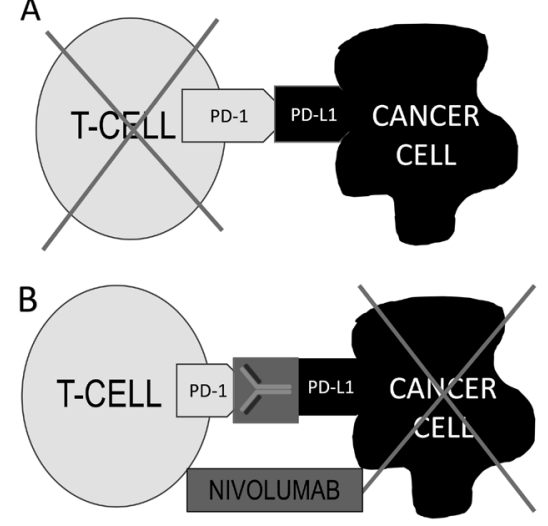

RECOGNITION AND DESTRUCTION OF CANCER CELL

\section{Figure 2}

(A) T cells are deactivated when programmed cell death-1 receptor (PD-1) binds to the PD-L1 ligand expressed on the cancer cell surface, which allows cancer cell survival. (B) When PD-1/PDL-1 inhibitors bind to the PD-1 or PDL-1 receptors respectively, T-cell is able to recognize cancer cells resulting in cancer cell destruction. Adapted/Translated by permission from Macmillan Publishers Ltd: Nature, Nature reviews clinical Oncology, Safety profiles of anti-CTLA-4 and anti-PD-1 antibodies alone and in combination. Boutros C, Tarhini A, Routier E, Lambotte O, Ladurie FL, Carbonnel F, Izzeddine H, Marabelle A, Champiat S, Berdelou A et al. 2016. 
it may be possible to predict individual risk, identify these patients earlier and prevent ICPI-induced metabolic decompensation. Meanwhile, the acuity of development of T1DM in this focused high-risk population may offer deeper understanding into the molecular pathways and help identify therapeutic targets for treating T1DM in the future.

\section{Somatostatin analogues and diabetes}

Somatostatin analogues like octreotide, lanreotide and pasireotide in addition to being the mainstay of treatment for acromegaly have been used for the treatment of refractory neuroendocrine tumors both for symptom control and as a cancer therapy agent (Van Op den Bosch et al. 2009). Somatostatin has a dual effect on both insulin and glucagon mediated by somatostatin receptors, sstr2 and sstr5, which are expressed in the pancreatic islet cells (Hauge-Evans et al. 2009). Somatostatin inhibits insulin release by activating sstr2 and sstr5 receptors and inhibits the release of glucagon by the activation of sstr2 receptor (Singh et al. 2007). Hence, a variable effect of somatostatin analogues on glucose homeostasis has been noted due to their characteristic affinity toward each of these receptors. Pasireotide has a 39-fold higher affinity to bind with sstr5 and a lower affinity toward sstr2 (Bruns et al. 2002). During a 24-week prospective study to investigate the efficacy and safety of using pasireotide in the treatment of acromegaly, hyperglycemia was the most common adverse event and reported in 54 out of 61 patients enrolled (88.5\%) and the mean HbA1c increased from 6.1 to $7.8 \%$ during week 12-24 of the study. In addition, at the end of 24 weeks, a baseline $\mathrm{HbA1c}$ of $>5.7 \%$ was determined to be the most important predictor for development of diabetes. Most patients who did not have a prior diagnosis of diabetes in the study were successfully managed with oral agents and only 3 out of $46(9.8 \%)$ required intensive management with insulin (Muhammad et al. 2018).

In contrast to this, hypoglycemia has been noted with octreotide due to its affinity toward suppressing glucagon production more than insulin production (Schmid \& Schoeffer 2004). With the use of these agents it is important to recognize their functional affinity to different somatostatin receptors dictates whether a patient will develop hyperglycemia or hypoglycemia. In the future, long-term follow-up studies are required to determine if the patients exposed to these drugs and did not develop diabetes require frequent monitoring and early intervention.

\section{Cancer therapies that induce insulin resistance}

The effect of cancer therapy on insulin resistance (IR) is best appreciated by understanding the molecular pathways involved in the development of IR. Insulin is a polar polypeptide hormone that binds to its cellsurface insulin receptor, which has extracellular $(\alpha)$ and intracellular ( $\beta$ ) domains. Binding of insulin to the $\alpha$ subunit initiates auto-phosphorylation and activation of the tyrosine kinase component of the $\beta$ domain. The activated tyrosine kinase phosphorylates insulin receptor substrate 1 (IRS-1), which when triggered, activates phosphatidylinositide-1 kinase (PI 3-kinase) that generates phosphatidylinositol phosphate 2 and 3 (PIP-2 and PIP3). PIP-3 phosphorylates the serine/threonine protein kinase Akt or protein kinase B (PKB), which has a broad range of actions including potentiation of membrane translocation of the glucose transporter GLUT4, which is required for insulin-mediated glucose transport across the cell membrane (Boucher et al. 2014).

From the perspective of cancer therapy, the insulin signaling pathway is of great interest since it is critical for cancer progression and hyperglycemia can be seen as a surrogate marker of successful blockade (Singh et al. 2014). In considering hyperglycemia as a common consequence of treatment with these agents, the established effect of diabetes on cancer mortality looms as a potentially important long-term consideration (Chang et al. 2004). Each of the therapies discussed below, target key elements of this pathway (Fig. 3 and Table 2).

\section{Tyrosine kinase inhibitors (TKI) and their relation to diabetes}

Tyrosine kinase activation of the intracellular $\beta$ domain of the insulin receptor is a key first step in insulin signaling and more generally activates a family of enzymes involved in cell proliferation, growth, cellular metabolism and angiogenesis (Arora \& Scholar 2005). Blocking these pathways is a key component for antiangiogenic therapies such as TKIs. Examples of these drugs include sorafenib, sunitinib, pazopanib, axitinib, vandetanib, lenvatinib, erlotinib, gefitinib and regorafenib which have been used to treat renal cell carcinoma, hepatocellular carcinoma, medullary thyroid cancer, pancreatic neuroendocrine tumors, gastrointestinal stromal tumor, adenosquamous cell carcinoma of the lung and small-cell lung cancer (Arora \& Scholar 2005, Li \& Lu 2018). 


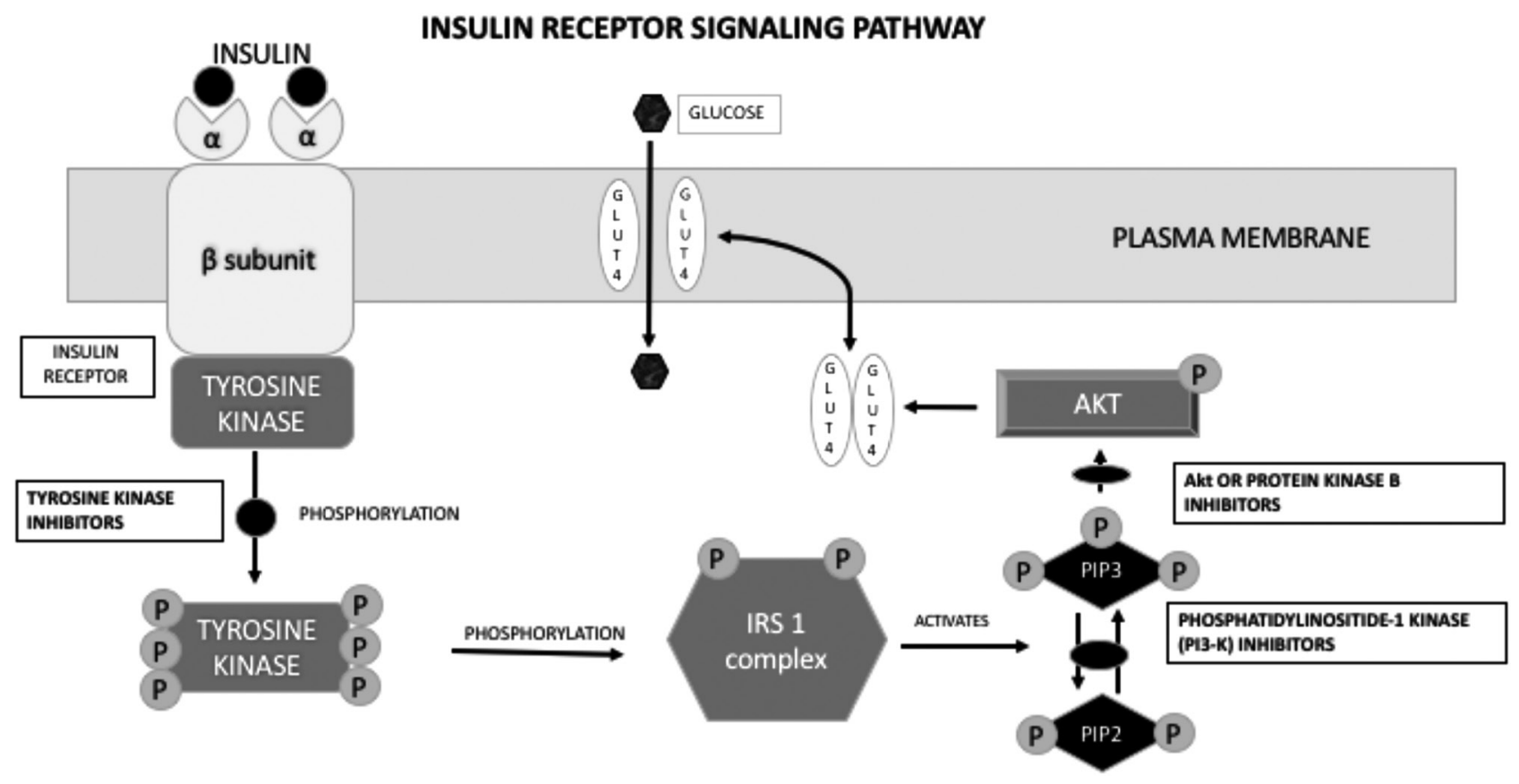

\section{Figure 3}

Insulin binds to its cell-surface insulin receptor, which has extracellular $(\alpha)$ and intracellular $(\beta)$ domains. Binding of insulin to the $\alpha$ subunit initiates auto-phosphorylation and activation of the tyrosine kinase component of the $\beta$ domain. The activated tyrosine kinase phosphorylates insulin receptor substrate 1 (IRS-1), which when triggered, activates phosphatidylinositide-1 kinase (PI 3-kinase) that generates phosphatidylinositol phosphate 2 and 3 (PIP-2 and PIP-3). PIP-3 phosphorylates the serine/threonine protein kinase Akt or protein kinase B (PKB), which have a broad range of actions including potentiation of membrane translocation of the glucose transporter GLUT4, which is required for insulin-mediated glucose transport across the cell membrane. Adapted/Translated by permission from Macmillan Publishers Ltd: Nature, Nature reviews clinical Oncology, Safety profiles of anti-CTLA-4 and anti-PD-1 antibodies alone and in combination. Boutros C, Tarhini A, Routier E, Lambotte O, Ladurie FL, Carbonnel F, Izzeddine H, Marabelle A, Champiat S, Berdelou A et al. 2016. (doi: 10.1038/nrclinonc.2016.58. Epub 2016 May 4).

While blocking TK activity may cause insulin resistance, the overall effect of TKI in preclinical models is to reverse both $\mathrm{T} 1$ and $\mathrm{T} 2$ diabetes, and these agents are being considered in diabetes drug development (Hägerkvist et al. 2006, Louvet et al. 2008, Malek \& Davis 2016). The mechanism of beneficial effects of TKI in diabetes is not fully understood, but in mice enhancement of beta cell mass was reported with the use of imatinib and sunitinib, a result that would be expected to compensate for IR (Hägerkvist et al. 2006). Additionally, mice pretreated with imatinib did not develop hyperglycemia after being exposed to the $\beta$-cell toxin streptozotocin suggesting a protective effect against beta cell apoptosis (Hägerkvist et al. 2006). In patients with preexisting diabetes receiving TKIs, mean blood glucose concentrations declined significantly with imatinib $(-9 \mathrm{mg} / \mathrm{dL})$, dasatinib $(-53 \mathrm{mg} / \mathrm{dL})$, sorafenib $(-12 \mathrm{mg} / \mathrm{dL})$ and sunitinib $(-14 \mathrm{mg} / \mathrm{dL})$ compared to normal controls. Remarkably, from this study 8 of the 17 patients with diabetes were able to discontinue their glucose-lowering medications, including insulin (Agostino et al. 2011). Hence, TKIs have been investigated as agents to treat and reverse T1DM
(Hägerkvist et al. 2006). While TKIs are being developed as a therapy for diabetes, these desirable off-target effects can be incorporated into management decisions for patients with preexisting diabetes.

\section{Phosphatidylinositide-1 kinase (PI3-K) inhibitors and insulin resistance}

PI3-K-protein kinase B (Akt)-mammalian target of rapamycin (mTOR) pathway is a key signaling pathway that regulates cellular proliferation, dehiscence and growth (Simioni et al. 2018). Mutations affecting the PI 3-Kinase pathway are present in many human cancer cells making it a target for therapeutics designed to inhibit cancer progression. In addition to being activated by insulin PI3-K is also activated by other growth regulators like epidermal growth factors, insulin-like growth factors and vascular endothelial growth factors making PI3K a key regulator of cell cycle checkpoints effecting apoptosis, proliferation and growth (Liu et al. 2009). However, blocking PI 3-kinase interferes with the normal process of insulin signaling that can result in insulin resistance. In 2014, 
Table 2 Cancer therapies that induce insulin resistance.

\begin{tabular}{|c|c|c|c|c|c|c|}
\hline Drug category & Drug name & Drug target & Clinical indications & $\begin{array}{l}\text { Type of } \\
\text { diabetes }\end{array}$ & $\begin{array}{l}\text { Mechanism of } \\
\text { development of } \\
\text { hyperglycemia }\end{array}$ & $\begin{array}{l}\text { Reported incidence } \\
\text { of hyperglycemia }\end{array}$ \\
\hline $\begin{array}{l}\text { Tyrosine kinase } \\
\text { inhibitors }\end{array}$ & $\begin{array}{l}\text { Sorafenib } \\
\text { Sunitinib } \\
\text { Pazopanib } \\
\text { Axitinib } \\
\text { Vandetanib } \\
\text { Lenvatinib } \\
\text { Regorafenib }\end{array}$ & $\begin{array}{l}\text { Block tyrosine } \\
\text { protein } \\
\text { Kinase activity }\end{array}$ & $\begin{array}{l}\text { Renal cell carcinoma } \\
\text { Hepatocellular } \\
\text { carcinoma } \\
\text { Medullary thyroid } \\
\text { cancer } \\
\text { Pancreatic } \\
\text { neuroendocrine } \\
\text { tumors } \\
\text { Gastrointestinal } \\
\text { stromal tumor } \\
\text { Small cell lung cancer }\end{array}$ & $\begin{array}{l}\text { Reverses } \\
\text { T1DM and } \\
\text { T2DM }\end{array}$ & Not known & Not known \\
\hline $\begin{array}{l}\text { Phosphatidylinosit } \\
\text { IDE-1 kinase (PI3-K) } \\
\text { inhibitors }\end{array}$ & $\begin{array}{l}\text { Idelalisib } \\
\text { Pilaralisib } \\
\text { Copanisib }\end{array}$ & $\begin{array}{l}\text { PI 3-Kinase } \\
\text { pathway }\end{array}$ & $\begin{array}{l}\text { Chronic lymphocytic } \\
\text { lymphoma }\end{array}$ & T2DM & $\begin{array}{l}\text { Blocking PI 3-kinase } \\
\text { interferes with } \\
\text { insulin signaling } \\
\text { resulting in insulin } \\
\text { resistance }\end{array}$ & $\begin{array}{l}28-30 \% \text { reported } \\
\text { incidence of } \\
\text { hyperglycemia }\end{array}$ \\
\hline $\begin{array}{l}\text { Akt or protein } \\
\text { kinase B inhibitors }\end{array}$ & $\begin{array}{l}\text { GSK690693 } \\
\text { MK2206 }\end{array}$ & $\begin{array}{l}\text { Akt/protein } \\
\text { kinase B }\end{array}$ & $\begin{array}{l}\text { Refractory or } \\
\text { relapsed } \\
\text { haematological } \\
\text { malignancies } \\
\text { Advanced breast } \\
\text { cancer } \\
\text { Ovarian cancer }\end{array}$ & T2DM & $\begin{array}{l}\text { 1. Reduces hepatic } \\
\text { glycogen } \\
\text { synthesis } \\
\text { 2. Induces hepatic } \\
\text { glycogenolysis } \\
\text { 3. Blocking insulin } \\
\text { signaling } \\
\text { resulting in } \\
\text { insulin resistance }\end{array}$ & Not known \\
\hline $\begin{array}{l}\text { Androgen } \\
\text { deprivation } \\
\text { therapy }\end{array}$ & $\begin{array}{l}\text { Leuprolide } \\
\text { Goserelin } \\
\text { Triptorelin } \\
\text { Histrelin }\end{array}$ & GNRH & Prostate cancer & T2DM & $\begin{array}{l}\text { 1. Hyperinsulinemia } \\
\text { 2. Change in body } \\
\text { fat composition }\end{array}$ & Not known \\
\hline
\end{tabular}

the FDA-approved idelalisib as the first PI3K inhibitor for use in chronic lymphocytic lymphoma (Yang et al. 2015). Even though idelalisib does not cause hyperglycemia, other drugs that target the same pathway, and currently being evaluated in clinical trials including pilaralisib and copanisib, have a $28-30 \%$ reported incidence of hyperglycemia (Nair \& Cheson 2016). It is expected that the clinical application of these agents will expand due to their effects on key cancer signaling pathways, making it important to understand the epidemiology and clinical course of drug-induced diabetes. In particular, it will be important to know whether hyperglycemia induced by PI3K inhibitors is reversible or permanent after therapy is discontinued.

\section{Protein kinase B (Akt) inhibitors and insulin resistance}

Phosphoinositide-dependent serine threonine protein kinase (protein kinase B, Akt) is a key intermediary protein in the insulin signaling pathway especially in skeletal muscle and adipose tissue. Signaling through
PI3-K/protein kinase B (Akt)/mammalian target of rapamycin (mTOR) is also one of the fundamental pathways regulating cellular proliferation and growth (Simioni et al. 2018). Thus, it has been a very active area in cancer therapy development since PI3K/Akt pathway mutations are essential for cancer cell proliferation and progression (Crouthamel et al. 2009). Drugs designed to target this pathway cause insulin resistance and glucose intolerance as an expected on-target effect due to its direct influence on the insulin signaling pathway (Crouthamel et al. 2009). It has also been noted that Akt2-knockout mice have significant fasting hyperglycemia, post-prandial hyperglycemia and hyperinsulinemia compared to WT mice (Cho et al. 2001). Since AKt is involved in insulindependent glucose transport across the cell membrane, the effect on fasting and on post meal hyperglycemia was studied in mice treated with GSK690693, a panAKT kinase inhibitor. The findings showed significantly higher and prolonged hyperglycemia in non-fasted mice treated with GSK690693 compared to mice fasted for $16 \mathrm{~h}$ prior to treatment with GSK690693. In addition, lower levels of hepatic glycogen (90\% lower) was noted 
in GSK690693-treated mice suggesting that Akt inhibition also reduced hepatic glycogen synthesis and induced hepatic glycogenolysis (Crouthamel et al. 2009). In the same study, the effect of common anti-hyperglycemics was evaluated in the mice treated with GSK690693. Pretreatment of mice with rosiglitazone for 7 days at a maximum dose of $5 \mathrm{mg} / \mathrm{kg}$ twice daily had no significant effect on the duration and severity of hyperglycemia. Furthermore, when insulin was added to rosiglitazone 30 min before starting treatment with GSK690693, there were only modest effects on the duration and severity of hyperglycemia. Based on these findings, it was suggested that Akt inhibitors cause hyperglycemia by a combination of mechanisms including insulin resistance, inhibition of glycogen synthesis and reduction of peripheral glucose uptake (Cho et al. 2001). GSK690693 and MK2206 are Akt inhibitors and are currently being investigated for treatment of refractory or relapsed hematological malignancies, advanced breast cancer and ovarian cancer. The results of these clinical trials are expected in the coming years and more data are needed to understand the effect and outcomes in humans especially due to the proposed multiple mechanisms of hyperglycemia noted in mice and the reported challenge providers face treating hyperglycemia with insulin and insulin sensitizers (https://clinicaltrials.gov/ct2/results?term=akt+inhibitors \&Search=Search, accessed 3/22/18).

\section{Androgen deprivation therapy and insulin resistance}

Prostate cancer is one of the most commonly diagnosed cancers in men. The effectiveness of androgen deprivation therapy, either surgically with bilateral orchiectomy or medically with gonadotrophin-releasing hormone agonist (GnRH), has resulted in 5-year survival of $86 \%$ of patients with locally invasive or metastatic prostate cancer (Keating et al. 2006). In contrast to these desired effects on prostate cancer, GnRH agonists have deleterious effects on the body fat composition, increasing body weight and percentage fat body mass, while decreasing lean body mass and muscle size in men with non-metastatic prostate cancer, which causes increased IR (Smith et al. 2002). In addition, a separate study reported a near doubling of fasting insulin levels $(6.89 \pm 4.84 \mathrm{mmol} / \mathrm{L}$ or $124 \pm 87.1 \mathrm{mg} /$ $\mathrm{dL}$ to $11.34 \pm 8.16 \mathrm{mmol} / \mathrm{L}$ or $204.1 \pm 146.9 \mathrm{mg} / \mathrm{dL}$ ) but a non-significant increase in fasting plasma glucose levels $(5.6 \mathrm{mmol} / \mathrm{L}$ or $100.8 \mathrm{mg} / \mathrm{dL}$ to $6.0 \mathrm{mmol} / \mathrm{L}$ or $108 \mathrm{mg} / \mathrm{dL})$ 3 months after androgen deprivation therapy was initiated with GnRH analogues (Dockery et al. 2003). Another observational study reported a higher risk of incident diabetes in patients treated with androgen deprivation therapy compared to non-treated patients and patients treated with bilateral orchiectomy (Keating et al. 2006). This further establishes the association of diabetes with androgen deprivation therapy.

In contrast to the increased incidence of several cancers in patients with diabetes, prostate cancer is an exception since men with diabetes have lower testosterone levels, which is considered protective against prostate cancer (Kasper \& Giovannucci 2006). However, when the effects of hyperinsulinemia and increase fat mass from $\mathrm{GnRH}$ analogues is considered, the impact of this treatment is complex.

\section{Cancer therapies that reduce insulin production and induce insulin resistance}

\section{Corticosteroids and diabetes}

Corticosteroids (CST) are not novel to cancer therapeutics since drugs like prednisone, dexamethasone and methylprednisolone have been used to treat cancer, suppress inflammation, and the immune response in multiple malignancies for several decades (Bartlett et al. 2001). In addition to the direct effect on cancer progression, the benefit of improved tolerance to chemotherapy, treatment of associated nausea and appetite suppression has made potent, long-acting steroids one of the most commonly prescribed drug classes in the field of oncology (Hesketh 2008). In contrast to the benefits seen in cancer patients, the undesirable effect of CST on blood glucose control has been clearly established since steroids not only exacerbate preexisting diabetes, but also induce hyperglycemia and precipitate diabetes in patients with no known prior history of diabetes (Van Raalte et al. 2009). Based on a single-center experience, about $68 \%$ patients treated with greater than $40 \mathrm{mg}$ or equivalent dose of prednisone daily for $>2$ days experienced hyperglycemia (Blood glucose $>200 \mathrm{mg} / \mathrm{dL}$ ) (Table 3). Among the patients who did not have a prior history of diabetes, $56 \%$ experienced at least one episode of hyperglycemia (Donihi et al. 2006). This indicates the high prevalence of hyperglycemia in the steroid-treated, cancer patients, which is often undertreated.

IR seen in steroid-induced diabetes follows a similar pattern to T2DM. About $60-80 \%$ patients treated with steroids, develop hyperglycemia, explained by specific targeted effects at the level of the muscle, adipose tissue and the liver, which are all key tissues for maintaining blood glucose homeostasis. In the normal fasting state, 


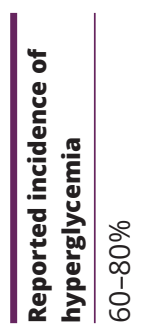

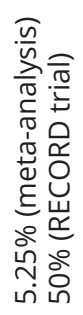

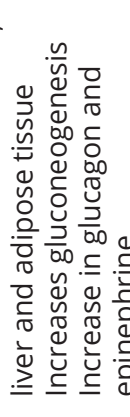

芩
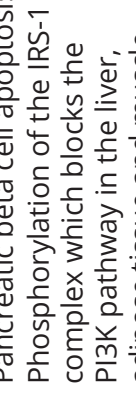

نं $\dot{+} \dot{+}$

\section{ก}

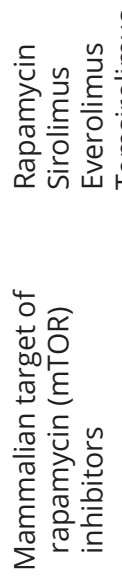

the liver produces glucose to maintain euglycemia. In a state of low insulin, gluconeogenesis and glycogenolysis provide glucose for oxidation primarily by neural tissues. Steroids accentuate this finely tuned system and increase endogenous glucose production by activating genes involved in gluconeogenesis and enhancing the release of gluconeogenic substrates such as alanine from skeletal muscle. Steroids also indirectly blunt the effect of insulin by enhancing the effect of counter-regulatory hormones like epinephrine and glucagon, which also contribute to increased hepatic insulin resistance (Ruzzin et al. 2005).

In the skeletal muscle, steroids inhibit the translocation of the GLUT4 glucose transporter resulting in insulin resistance. Here, insulin-dependent glucose transport into the cells is inhibited by $30-50 \%$ in the presence of CST. In addition, there is also a $70 \%$ reduction in glycogen synthesis in the muscle resulting in hyperglycemia. In adipose tissue, CST increases the breakdown of lipids by inducing lipolysis and raising local accumulation of nonsterified fatty acids, a mechanism that has been associated with greater increasing insulin resistance (Perez et al. 2014). Apart from these effects on the liver, muscle and adipose tissue, it is postulated that CST has an effect on insulin secretion by direct effect on pancreatic beta cell by induction of apoptosis (Ranta 2006).

From the above, it is clear that CST causes IR and, to some extent, insulin secretory defects resulting in hyperglycemia and since it is commonly prescribed in the oncology population it is important to identify early and provide expectant treatment with a regimen adjusted for the type, frequency and duration of CST being prescribed. Clear communication between oncologists and providers managing DM can abbreviate the duration and severity of hyperglycemia. While managing hyperglycemia secondary to steroids attention must be paid to whether there is a preexisting history of T2DM where higher levels of IR is expected.

\section{Mammalian target of rapamycin (mTOR) inhibitors and diabetes}

mTOR inhibitors are a group of drugs that inhibit the PI3K-Akt mammalian target of rapamycin (mTOR) pathway. mTOR inhibitors like rapamycin, sirolimus and everolimus have been in use as organ transplant anti-rejection therapy for several years now (Touzot et al. 2012). More recently additional benefits of these agents as a cancer therapy has been identified due the inhibitory effect on critical pathways in carcinogenesis. Everolimus and temsirolimus have been recently approved for 
advanced neuroendocrine tumors except for functional midgut tumors with carcinoid syndrome, advanced renal cell carcinoma that fails treatment with first line agents, mantle cell lymphoma and breast cancer (Yao et al. 2011).

Two major clinical trials involving the use of everolimus have reported significantly higher rates of hyperglycemia (fasting blood glucose $>126 \mathrm{mg} / \mathrm{dL}$ ) including the RECORD 1 and the BOLERO trial. In the RECORD trial for advanced renal cell carcinoma patients, about 50\% subjects reported hyperglycemia and $12 \%$ reported severe hyperglycemia compared to $1 \%$ in the placebo controlled group (Motzer et al. 2008). Similarly, during the BOLERO 1 trial for advanced HER2-positive breast cancer, everolimus-treated patients reported a higher incidence of hyperglycemia compared to placebo-treated patients (12\% compared to 5\%; Hurvitz et al. 2015). A meta-analysis of 24 clinical trials including 4261 patients showed an incidence rate ratio of any grade hyperglycemia (fasting blood glucose $>126 \mathrm{mg} / \mathrm{dL})$ as 2.95 (95\% CI, 2.14, 4.05) and severe grade 3 and 4 hyperglycemia (random blood glucose above $251 \mathrm{mg} / \mathrm{dL})$ as 5.25 (95\% CI, 3.07, 9.00) further supporting this association (Sivendran et al. 2014; Table 3).

Mechanism of hyperglycemia from mTOR inhibitors: mTOR is a kinase belonging to a family of enzymes packaged into 2 complexes, mTOR complex 1 and 2 (mTORC 1 and mTORC 2) that have distinct functions. When activated the mTORC 1 pathway promotes protein synthesis, cellular growth and proliferation with inhibition of autophagy and the mTORC 2 pathway activation promotes cellular proliferation and cell survival making these important targets for cancer treatment. With regard to diabetes, mTOR plays an important role in balancing insulin resistance and pancreatic beta cell function. mTORC 1 in addition to the above mentioned role in cellular proliferation causes the phosphorylation of the IRS-1 complex, which blocks the PI3K pathway in the liver, adipose tissue and muscle-promoting tissue insulin resistance (Khamzina et al. 2005). In contrast to this, mTORC 1 activation increases beta cell mass and proliferation of beta cells (Rachdi etal. 2008). Hence overall, mTOR pathway activation is involved in maintaining a balance in energy metabolism. With the use of mTOR inhibitors this balance is disrupted. Theoretically, blocking mTORC 1 should reduce insulin resistance, but this is not the case since the ability to cause insulin resistance depends on the dose and duration of mTOR inhibitor use where too much or too little inhibition can cause insulin resistance (Houde et al. 2010, Fang et al. 2013).

As described previously, mTORC 1 is also involved in pancreatic beta cell proliferation and inhibiting this will inadvertently result in reduced beta cell mass and proliferation. A 33\% reduction in glucose-dependent insulin secretion was observed following treatment with rapamycin. In addition, in animal models, treatment with rapamycin reduced beta cell mass by about $50 \%$ due to increased cellular apoptosis (Fraenkel et al. 2008). This aspect of mTOR inhibitors incited the use of these agents for the therapeutic purpose of treating insulinomas due to their 'desirable' effect of reducing beta cell mass (Kulke et al. 2009).

Due to this established association between mTOR inhibitors and hyperglycemia, it is now recommended to screen patients with a hemoglobin A1c and a fasting plasma glucose before initiation of mTOR inhibitors and to repeat plasma glucose every 2 weeks for a month and then monthly after until treatment continues. This has enabled early recognition and treatment of hyperglycemia in these patients. However, the same level of scrutiny is not performed for newer agents where hyperglycemia is poorly characterized.

\section{Conclusion}

Development of hyperglycemia and diabetes is associated with increased mortality in commonly encountered cancers. New advances in cancer therapy including immune check point inhibitors, TKI, PI3-K inhibitors and Akt inhibitors promise better oncologic outcomes, but it seems likely that metabolic side effects will be an important consequence that will require clinical attention and better mechanistic understanding. The data available from preclinical models and human studies with the new cancer therapies suggest that the general pathology of common forms of diabetes, namely insulin resistance and/ or impaired insulin secretion, can be exacerbated by novel anti-cancer agents. This is not surprising considering that signaling pathways targeted by new cancer therapies are also central to cellular metabolism. The long-term consequences of developing diabetes secondary to these new anti-cancer agents are poorly understood because of limited epidemiology. Specifically, it will be important to know the permanence or reversibility drug-induced diabetes, the risk of common macro and microvascular diabetic complications they confer, and the ultimate impact on cancer prognosis. Overall, understanding the relationship between specific cancers, new cancer therapies and secondary diabetes is important to optimize patient care. Moreover, this understanding may lead to new insights into diabetes pathogenesis and applications that can be applied beyond the field of oncology. 


\section{Declaration of interest}

The authors declare that there is no conflict of interest that could be perceived as prejudicing the impartiality of this review.

\section{Funding}

This work did not receive any specific grant from any funding agency in the public, commercial, or not-for-profit sector.

\section{Author contribution statement}

Afreen I Shariff: manuscript idea, preparation of the manuscript and data collection. Sohail Syed: Preparation of the manuscript. Rebacca Shelby: manuscript review. Jeremy Force: manuscript review. Jeffrey Clarke: manuscript review. David D’Alessio: manuscript review. Leonor Corsino: manuscript idea, data collection and manuscript review.

\section{References}

Abdel-Rahman O, ElHalawani H \& Fouad M 2016 Risk of endocrine complications in cancer patients treated with immune check point inhibitors: a meta-analysis. Future Oncology 12 413-425. (https://doi. org/ 10.2217/fon.15.222)

Agostino NM, Chinchilli VM, Lynch CJ, Koszyk-Szewczyk A, Gingrich R, Sivik J \& Drabick JJ 2011 Effect of the tyrosinekinaseinhibitors (sunitinib, sorafenib, dasatinib, andimatinib) on blood glucose levels in diabetic and nondiabetic patients in general clinical practice. Journal of Oncology Pharmacy Practice 17 197-202. (https://doi. org/10.1177/1078155210378913)

Ansari MJ, Salama AD, Chitnis T, Smith RN, Yagita H, Akiba H, Yamazaki T, Azuma M, Iwai H, Khoury SJ, et al 2003 The programmed death-1 (PD-1) pathway regulates autoimmune diabetes in nonobese diabetic (NOD) mice. Journal of Experimental Medicine 198 63-69. (https://doi.org/ 10.1084/jem.20022125)

Arora A \& Scholar EM 2005 Role of tyrosine kinase inhibitors in cancer therapy. Journal of Pharmacology and Experimental Therapeutics $\mathbf{3 1 5}$ 971-979. (https://doi.org/10.1124/jpet.105.084145)

Au TH, Wang K, Stenehjem D \& Garrido-Laguna I 2017 Personalized and precision medicine: integrating genomics into treatment decisions in gastrointestinal malignancies. Journal of Gastrointestinal Oncology 8 387-404. (https://doi.org/10.21037/jgo.2017.01.04)

Barroso-Sousa R, Barry WT, Garrido-Castro AC, Hodi FS, Min L, Krop IE \& Tolaney SM 2018 Incidence of endocrine dysfunction following the use of different inhibitor regimens: a systematic review and meta-analysis. JAMA 4 173-182. (https://doi.org/10.1001/ jamaoncol.2017.3064)

Bartlett NL, Petroni GR, Parker BA, Wagner ND, Gockerman JP, Omura GA, Canellos GP, Robert M, Johnson JL \& Peterson BA 2001 Dose-escalated cyclophosphamide, doxorubicin, vincristine, prednisone, and etoposide (CHOPE) chemotherapy for patients with diffuse lymphoma: Cancer and Leukemia Group B studies 8852 and 8854. Cancer 92 207-217. (https://doi.org/10.1002/10970142(20010715)92:2<207::AID-CNCR1311>3.0.CO;2-D)

Boucher J, Kleinridders A \& Kahn RC 2014 Insulin receptor signaling in normal and insulin-resistant states. Cold Spring Harbor Perspectives in Biology 6 pii: a009191. (https://doi.org/ 10.1101/cshperspect. a009191)

Boutros C, Tarhini A, Routier E, Lambotte O, Ladurie FL, Carbonnel F, Izzeddine H, Marabelle A, Champiat S, Berdelou A, et al. 2016 Safety profiles of anti-CTLA-4andanti-PD-1antibodies alone and in combination. Nature Reviews Clinical Oncology 13 473-486. (https:// doi.org/ 10.1038/nrclinonc.2016.58)
Bruns C, Lewis I, Briner U, Meno-Tetang G \& Weckbecker G 2002 A novel somatostatin peptidomimetic with broad somatotropin release inhibiting factor (SRIF) receptor binding and a unique antisecretory profile. European Journal of Endocrinology 146 707-716. (https://doi. org/10.1530/eje.0.1460707)

Byun DJ, Wolchok JD, Rosenberg LM \& Girotra M 2017 Cancer immunotherapy - immune checkpoint blockade and associated endocrinopathies. Nature Reviews Endocrinology 13 195-207. (https:// doi.org/ 10.1038/nrendo.2016.205)

Campbell PT, Newton CC, Patel AV, Jacobs EJ \& Gapstur SM 2012 Diabetes and cause-specific mortality in a prospective cohort of one million U.S. Adults. Diabetes Care 35 1835-1844. (https://doi. org/10.2337/dc12-0002)

Chang L, Chiang S-H \& Saltiel AR 2004 Insulin signaling and the regulation of glucose transport. Molecular Medicine 10 65-71. (https://doi.org/10.2119/2005-00029.Saltiel)

Cho H, Mu J, Kim JK, Thorvaldsen JL, Chu Q, Crenshaw EB 3rd, Kaestner KH, Bartolomei MS, Shulman GI \& Birnbaum MJ 2001 Insulin resistance and a diabetes mellitus-like syndrome in mice lacking the protein kinase Akt2 (PKB). Science 292 1728-1731. (https://doi.org/10.1126/science.292.5522.1728)

Crouthamel MC, Kahana JA, Korenchuk S, Zhang SY, Sundaresan G, Eberwein DJ, Brown KK \& Kumar R 2009 Mechanism and management of AKT inhibitor-induced hyperglycemia. Clinical Cancer Research 15 217-225. (https://doi.org/ 10.1158/1078-0432. CCR-08-1253)

Culver ME, Gatesman ML, Mancl EE \& Lowe DK 2011 Ipilimumab: a novel treatment for metastatic melanoma. Annals of Pharmacotherapy 45 510-519. (https://doi.org/ 10.1345/aph.1P651)

Delovitch TL \& Singh B 1997 The nonobese diabetic mouse as a model of autoimmune diabetes: immune dysregulation gets the NOD. Immunity 7 727-738. (https://doi.org/10.1016/S10747613(00)80392-1)

Diesendruck Y \& Benhar I 2017 Novel immune check point inhibiting antibodies in cancer therapy-Opportunities and challenges. Drug Resistance Updates 30 39-47. (https://doi.org/ 10.1016/j. drup.2017.02.001)

Dockery F, Bulpitt CJ, Agarwal S, Donaldson M \& Rajkumar C 2003 Testosterone suppression in men with prostate cancer leads to an increase in arterial stiffness and hyperinsulinaemia. Clinical Science 104 195-201. (https://doi.org/ 10.1042/CS20020209)

Donihi AC, Raval D, Saul M, Korytkowski MT \& DeVita MA 2006 Prevalence and predictors of corticosteroid-related hyperglycemia in hospitalized patients. Endocrine Practice 12 358-362. (https://doi.org/ 10.4158/EP.12.4.358)

El-Seraq HB, Hampel H \& Javadi F 2006 The association between diabetes and hepatocellular carcinoma: a systematic review of epidemiology. Clinical Gastroenterology and Hepatology 4 369-380. (https://doi.org/ 10.1016/j.cgh.2005.12.007)

Fang Y, Westbrook R, Hill C, Boparai RK, Arum O, Spong A, et al. 2013 Duration of rapamycin treatment has differential effects on metabolism in mice. Cell Metabolism 17 456-62. (https://doi. org/10.1016/j.cmet.2013.02.008)

Fraenkel M, Ketzinel-Gilad M, Ariav Y, Pappo O, Karaca M, Castel J, Berthault MF, Magnan C, Cerasi E, Kaiser N, et al. 2008 mTOR inhibition by rapamycin prevents betacelladaptation tohyperglycemia and exacerbates the metabolic state in type 2 diabetes. Diabetes 57 945-57. (https://doi.org/ 10.2337/db07-0922)

Hägerkvist R, Makeeva N, Elliman S \& Welsh N 2006 Imatinib mesylate (Gleevec) protects against streptozotocin-induced diabetes and islet cell death in vitro. Cell Biology International 30 1013-1017.

Hauge-Evans AC, King AJ, Carmignac D, Richardson CC, Robinson IC, Low MJ, Christie MR, Persaud SJ \& Jones PM 2009 Somatostatin secreted by islet delta-cells fulfills multiple roles as a paracrine regulator of islet function. Diabetes 58 403-411. (https://doi. org/10.2337/db08-0792) 
Hesketh PJ 2008 Chemotherapy-induced nausea and vomiting. New England Journal of Medicine 358 2482-2494. (https://doi.org/ 10.1056/ NEJMra0706547)

Hodi FS, O'Day SJ, McDermott DF, Weber RW, Sosman JA, Haanen JB, Gonzales R, Robert C, Schadendorf D, Hassel JC, et al. 2010 Improved survival with ipilimumab in patients with metastatic melanoma. New England Journal of Medicine 363 711-723. (https:// doi.org/10.1056/NEJMoa1003466)

Houde VP, Brule' S, Festuccia WT, Blanchard P-G, Bellmann K, Deshaies Y \& Marette A 2010 Chronic rapamycin treatment causes glucose intolerance and hyperlipidemia by upregulating hepatic gluconeogenesis and impairing lipid deposition in adipose tissue. Diabetes 59 1338-1348. (https://doi.org/10.2337/db09-1324)

Hughes J, Vudattu N, Sznol M, Gettinger S, Kluger H, Lupsa B, Herold KC, Zhang Q, Liu D, Dreosti LM, et al. 2015 Precipitation of autoimmune diabetes with anti-PD-1immunotherapy. Diabetes Care 38 e55-e57.

Hurvitz SA, Andre F, Jiang Z, Shao Z, Mano MS, Neciosup SP, Tseng LM, 2015 Combinationof everolimus with trastuzumab plus paclitaxel as first-line treatment for patients withHER2- positive advanced breast cancer (BOLERO-1): a phase 3, randomised, doubleblind, multicentre trial. Lancet Oncology 16 816-829. (https://doi.org/10.1016/S14702045(15)00051-0)

Jonathan K, Zachary S, Deepak K, Paul K \& Stuart W 2017 Immune checkpoint inhibitor-associated type 1 diabetes mellitus: case series, review of the literature, and optimal management. Case Reports in Oncology 10 897-909.

Kasper JS \& Giovannucci E 2006 A meta-analysis of diabetes mellitus and the risk of prostate cancer. Cancer Epidemiology, Biomarkers and Prevention 15 2056-2062. (https://doi.org/10.1158/1055-9965.EPI-060410)

Keating NL, O’Malley AJ \& Smith MR 2006 Diabetes and cardiovascular disease during androgen deprivation therapy for prostate cancer. Journal of Clinical Oncology 24 4448-4456. (https://doi.org/10.1200/ JCO.2006.06.2497)

Khamzina L, Veilleux A, Bergeron S \& Marette A 2005 Increased activation of the mammalian target of rapamycin pathway in liver and skeletal muscle of obese rats: possible involvement in obesitylinked insulin resistance. Endocrinology 146 1473-1481. (https://doi. org/10.1210/en.2004-0921)

Kulke MH, Bergsland EK \& Yao JC 2009 Glycemic control in patients with insulinoma treated with everolimus. New England Journal of Medicine 360 195-197. (https://doi.org/10.1056/NEJMc0806740)

Li C \& Lu H 2018 Adenosqaumous carcinoma of the lung. OncoTargets and Therapy 11 4829-4835. (https://doi.org/ 10.2147/OTT.S164574. eCollection 2018)

Liu P, Cheng H, Roberts TM \& Zhao JJ 2009 Targeting the phosphoinositide 3-kinase (PI3K) pathway in cancer. Nature Reviews Drug Discovery 8 627-644. (https://doi.org/10.1038/nrd2926)

Louvet C, Szot GL, Lang J, Lee MR, Martinier N, Bollag G, Zhu S, Weiss A \& Bluestone JA 2008 Tyrosine kinase inhibitors reverse type 1 diabetes in nonobese diabetic mice. PNAS 105 18895-18900. (https://doi.org/ 10.1073/pnas.0810246105)

Malek R \& Davis SN 2016 Tyrosine kinase inhibitors under investigation for the treatment oftype II diabetes. Expert Opinion on Investigational Drugs 25 287. (https://doi.org/10.1517/13543784.2016.1142531)

Motzer RJ, Escudier B, Oudard S, Hutson TE, Porta C, Bracarda S, Grünwald V, Thompson JA, Figlin RA, Hollaender N, et al., RECORD-1 Study Group. 2008 Efficacy of everolimus in advanced renal cell carcinoma: a double-blind, randomised, placebo. Lancet 372 449-456. (https://doi.org/10.1016/S0140-6736(08)61039-9)

Muhammad A, Lely AJVD, Delhanty PJD, Dallenga AHG, Haitsma IK, Janssen JAMJL \& Neggers SJCMM 2018 Efficacy and safety of switching to pasireotide inpatients with acromegaly controlled with pegvisomant and first-generation somatostatin analogues (PAPE study). Journal of Clinical Endocrinology and Metabolism 103 586-595. (https://doi.org/10.1210/jc.2017-02017)

Nair KS \& Cheson B 2016 The role of idelalisib in the treatment of relapsed and refractory chronic lymphocytic leukemia. Therapeutic Advances in Hematology 7 69-84. (https://doi.org/ $10.1177 / 2040620715625966)$

Perez A, Jansen-Chaparro S, Saigi I, Bernal-Lopez MR, Miñambres I \& Gomez-Huelgas R 2014 Glucocorticoid-induced hyperglycemia. Journal of Diabetes 6 9-20. (https://doi.org/10.1111/17530407.12090)

Pérez-Herrero E \& Fernández-Medarde A 2015 Advanced targeted therapies in cancer: drug nanocarriers, the future of chemotherapy. European Journal of Pharmaceutics and Biopharmaceutics 93 52-79. (https://doi.org/ 10.1016/j.ejpb.2015.03.018)

Rachdi L, Balcazar N, Osorio-Duque F, Elghazi L, Weiss A, Gould A, Chang-Chen KJ, Gambello MJ \& Bernal-Mirzrachi E 2008 Disruption of Tsc 2 in pancreatic beta cellsinduces beta cell mass expansion and improved glucose tolerance in a TORC1-dependentmanner. PNAS 105 9250-9255. (https://doi.org/10.1073/pnas.0803047105)

Ranta F 2006 Dexamethasone induces cell death in insulin-secreting cells, an effect reversed by exendin-4. Diabetes 55 1380-1390. (https://doi.org/10.2337/db05-1220)

Robert C, Long GV, Brady B, Dutriaux C, Maio M, Mortier L, Hassel JC, Rutkowski P, McNeil C, Kalinka-Warzocha E, et al. 2015 Nivolumab in previously untreated melanoma without BRAF mutation. New England Journal of Medicine 372 320-330. (https://doi.org/10.1056/ NEJMoa1412082)

Ruzzin J, Wagman AS \& Jensen J 2005 Glucocorticoid-induced insulin resistance in skeletal muscles: defects in insulin signaling and the effects of a selective glycogen synthase kinase-3 inhibitor. Diabetologia 48 2119-2130. (https://doi.org/10.1007/s00125-0051886-0)

Ryder M, Callahan M, Postow MA, Wolchok J \& Fagin JA 2014 Endocrine-related adverse events following ipilimumab in patients with advanced melanoma: a comprehensive retrospective review from a single institution. Endocrine-Related Cancer 21 371-381. (https://doi.org/ 10.1530/ERC-13-0499)

Salvatore MC, Agnese B, Paolo M, Liana DeV, Roberto S \& Francesco T 2013 Endocrine Side Effects Induced by Immune Checkpoint Inhibitors. Journal of Clinical Endocrinology and Metabolism 98 1361-1375. (https://doi.org/ 10.1210/jc.2012-4075)

Schmid HA \& Schoeffter P 2004 Functional activity of the multiligand analog SOM230 at human recombinant somatostatin receptor subtypes supports its usefulness in neuroendocrine tumors. Neuroendocrinology 80(Supplement 1) 47-50. (https://doi. org/10.1159/000080741)

Simioni C, Martelli AM, Zauli G, Vitale M, McCubrey JA, Capitani S \& Neri LM 2018 Targeting thephosphatidylinositol 3-kinase/Akt/ mechanistic target of rapamycinsignaling pathway in B-lineage acute lymphoblastic leukemia: an update. Journal of Cellular Physiology 233 6440-6454. (https://doi.org/ 10.1002/jcp.26539)

Simpson GR, Relph K, Harrington K, Melcher A \& Pandha H 2016 Cancer immunotherapy via combining oncolytic virotherapy with chemotherapy: recent advances. Oncolytic Virotherapy 5 1-13. (https://doi.org/10.2147/OV.S66083)

Singh V, Brendel MD, Zacharias S, Mergler S, Jahr H, Wiedenmann B, Bretzel RG, Plo“ckinger U \& Strowski MZ 2007 Characterization of somatostatin receptor subtype-specific regulation of insulin and glucagon secretion: an in vitro study on isolated human pancreatic islets. Journal of Clinical Endocrinology and Metabolism 92 673-680. (https://doi.org/10.1210/jc.2006-1578)

Singh P, Alex JM \& Bast F 2014 Insulin receptor (IR) and insulin-like growth factor receptor 1 (IGF-1R) signaling systems: novel treatment strategies for cancer. Medical Oncology 31 805. (https://doi.org/ $10.1007 /$ s12032-013-0805-3) (c) 2019 Society for Endocrinology Published by Bioscientifica Ltd. Printed in Great Britain 
Sivendran S, Agarwal N, Gartrell B, Ying J, Boucher KM, Choueiri TK, et al. 2014 Metabolic complications with the use of mTOR inhibitors for cancer therapy. Cancer Treatment Reviews 40 190-196. (https:// doi.org/10.1016/j.ctrv.2013.04.005)

Smith MR, Finkelstein JS, McGovern FJ, Zietman AL, Fallon MA, Schoenfeld DA \& Kantoff PW 2002 Changes in body composition during androgen deprivation therapy for prostate cancer. Journal of Clinical Endocrinology and Metabolism 87 599-603. (https://doi. org/10.1210/jcem.87.2.8299)

Touzot M, Soulillou JP \& Dantal J 2012 Mechanistic target of rapamycin inhibitors in solid organ transplantation: from benchside to clinical use. Current Opinion in Organ Transplantation 17 626-33. (https://doi. org/10.1097/MOT.0b013e32835a4be2)

Van Op den Bosch J, Adriaensen D, Van Nassauw L \& Timmermans JP 2009 The role(s) of somatostatin, structurally related peptides and somatostatin receptors in the gastrointestinal tract: a review. Regulatory Peptides 156 1-8. (https://doi.org/10.1016/j. regpep.2009.04.003)

Van Raalte DH, Ouwens DM \& Diamant M 2009 Novel insights into glucocorticoid-mediated diabetogenic effects: towards expansion of therapeutic options? European Journal of Clinical Investigation 39 81-93. (https://doi.org/ 10.1111/j.1365-2362.2008.02067)
Webster RM 2014 The immune checkpoint inhibitors: where are we now? Nature Reviews Drug Discovery 13 883-884. (https://doi. org/10.1038/nrd4476)

Wolchok JD, Neyns B, Linette G, Negrier S, Lutzky J, Thomas L, Waterfield W, Schadendorf D, Smylie M, Guthriee T Jr, et al. 2010 Ipilimumab monotherapy in patients with pretreated advanced melanoma: a randomised, double-blind, multicentre, phase 2, doseranging study. Lancet Oncology 11 155-164. (https://doi.org/10.1016/ S1470-2045(09)70334-1)

Yang Y \& Yee D 2012 Targeting insulin and insulin-like growth factor signaling in breast cancer. Journal of Mammary Gland Biology and Neoplasia 17 251-261. (https://doi.org/10.1007/s10911-012-9268-y)

Yang Q, Modi P, Newcomb T, Quéva C \& Gandhi V 2015 Idelalisib firstin-class PI3K delta inhibitor for the treatment of chronic lymphocytic leukemia, small lymphocytic leukemia, and follicular lymphoma. Clinical Cancer Research 21 1537-1542. (https://doi. org/10.1158/1078-0432.CCR-14-2034)

Yao JC, Shah MH, Ito T, Bohas CL, Wolin EM, Van Cutsem E, Hobday TJ, Okusaka T, Capdevila J, de Vries EGE, et al. 2011 Everolimus for advanced pancreaticneuroendocrine. New England Journal of Medicine 364 514-523. (https://doi.org/ 10.1056/ NEJMoa1009290)

Received in final form 1 October 2018

Accepted 25 October 2018
(C) 2019 Society for Endocrinology Published by Bioscientifica Ltd. Printed in Great Britain 